University of Nebraska - Lincoln

DigitalCommons@University of Nebraska - Lincoln

Sociology Department, Faculty Publications

Sociology, Department of

$9-2013$

\title{
The differential contributions of teen drinking homophily to new and existing friendships: An empirical assessment of assortative and proximity selection mechanisms
}

\author{
Jacob E. Cheadle \\ University of Nebraska-Lincoln, \\ Michael Stevens \\ University of Nebraska-Lincoln \\ Deadric T. Williams \\ University of Nebraska-Lincoln, dwilliams9@unl.edu \\ Bridget J. Goosby \\ University of Nebraska-Lincoln, bgoosby2@unl.edu
}

Follow this and additional works at: https://digitalcommons.unl.edu/sociologyfacpub

Cheadle, Jacob E.; Stevens, Michael; Williams, Deadric T.; and Goosby, Bridget J., "The differential contributions of teen drinking homophily to new and existing friendships: An empirical assessment of assortative and proximity selection mechanisms" (2013). Sociology Department, Faculty Publications. 219.

https://digitalcommons.unl.edu/sociologyfacpub/219

This Article is brought to you for free and open access by the Sociology, Department of at DigitalCommons@University of Nebraska - Lincoln. It has been accepted for inclusion in Sociology Department, Faculty Publications by an authorized administrator of DigitalCommons@University of Nebraska - Lincoln. 
Published in Social Science Research 42:5 (September 2013), pp. 1297-1310; doi: 10.1016/j.ssresearch.2013.05.001

Copyright (c) 2013 Elsevier Inc. Used by permission.

Submitted June 7, 2012; revised April 22, 2013; accepted May 6, 2013; published online May 21, 2013.

\title{
The differential contributions of teen drinking homophily to new and existing friendships: An empirical assessment of assortative and proximity selection mechanisms
}

\author{
Jacob E. Cheadle, Michael Stevens, Deadric T. Williams, and Bridget J. Goosby \\ University of Nebraska-Lincoln, 737 Oldfather Hall, Lincoln, NE 68588-0324
}

\begin{abstract}
Alcohol use is pervasive in adolescence. Though most research is concerned with how friends influence drinking, alcohol is also important for connecting teens to one another. Prior studies have not distinguished between new friendship creation, and existing friendship durability, however. We argue that accounting for distinctions in creation-durability processes is critical for understanding the selection mechanisms drawing drinkers into homophilous friendships, and the social integration that results. In order to address these issues, we applied stochastic actor based models of network dynamics to National Longitudinal Study of Adolescent Health data. Adolescents only modestly prefer new friendships with others who drinker similarly, but greatly prefer friends who indirectly connect them to homophilous drinkers. These indirect homophilous drinker relationships are shorter lived, however, and suggest that drinking is a social focus that connects adolescents via proximity, rather than assortativity. These findings suggest that drinking leads to more situational and superficial social integration.
\end{abstract}

Keywords: Alcohol, Adolescence, Network

\section{Introduction}

Alcohol use is a common social activity in adolescence that is not condoned by adults, but is central to adolescent society (Coleman, 1961). By 12th grade over $70 \%$ of adolescents try alcohol and noncontinuation rates are below 10\% (Johnston et al., 2011). Moreover, 50\% of 12th graders report that most or all of their friends drink alcohol ${ }^{1}$ frequently, and 75\% report that one or more friends drink until drunk each week (Johnston et al., 2008). Not surprisingly, many US high schools are "party climates" and few are completely drinker-free (Crosnoe, 2011). Given the commonality and social embeddedness of alcohol use, and the fact that teens routinely expose each other to it, drinking should be considered more than a risk behavior (i.e., Hingson et al., 2009). It is an important avenue by which adolescents connect socially with peers while expanding their social networks away from adult supervision (Steinberg and Morris, 2001).

We emphasize friend selection, rather than repeat the more common focus on friend influence (Ali and Dwyer, 2010; Bauman and Ennett, 1996). Selection is a theoretically important social process for understanding social integration, a core sociological idea that plays a well-documented role in shaping the life course (Berkman et al., 2000; Umberson et al., 2010). The purpose of this study, therefore, is to examine the role of drinking in two critical dimensions of adolescent friendships: the creation of new close friendships, and the subsequent durability of those relationships. Our focus on homophily ("birds of a feather flock together") reflects the fact that friend similarity is a common pattern of social relationships across the life course (McPherson et al., 2001) and in diverse characteristics in adolescence (e.g., Cheadle and Goosby, 2012; Cheadle and Schwadel, 2012; Kreager and Haynie, 2011).

1. For the sake of brevity, we will frequently use "drink" instead of "drink alcohol" or "alcohol use." 
Though integration is usually defined as the existence, quantity, or frequency of social relationships and contact (House et al., 1988; Falci and McNeely, 2009), adolescent friendships are fluid and change frequently (Crosnoe et al., 2008). We propose that integrative connections among drinkers are characterized both by homophilous close friendships and increased friendship durability. Such a pattern, we argue, is consistent with an assortative selection mechanism. A proximity-based selection mechanism, however, suggests a different connection pattern over time. If drinking and partying ${ }^{2}$ are foci that organize adolescent social opportunities and resulting friendships, it may foster friendships among teens with similar drinking levels. The many social opportunities partying affords, however, may also undercut the durability of homophilous friendships. Best friendships homophilous on drinking would then result in more situational and superficial integration because relationships are of shorter duration.

How drinking influences friendships, and thus social integration, is a challenging methodological problem (Wasserman, 1980a, 1980b). In order to address the statistical issues, we apply longitudinal stochastic actor based (SAB) models of social network dynamics (Snijders, 1996, 2001) to 13 schools from the National Longitudinal Study of Adolescent Health (Add Health). The SAB approach allows us to study friendship change and stability dynamics using evaluation (tie presence), creation (new ties), and endowment (durability of existing ties) processes, which together reveal the dynamic interplay between drinking trajectories and close friendship patterns. Theoretically, this approach helps to clarify the mechanisms by which drinking connects youth, and the corresponding implications for the social integration that results.

\section{Literature review}

\subsection{Background}

High teen drinking prevalence and embeddedness of use in party environments away from adult supervision tightly couples alcohol with diverse social opportunities. Adolescents choose whether or not to drink in party settings, but also whether or not to participate in them at all (Albert and Steinberg, 2011). Friendship is a valuable crucible in which to study these processes because friends not only provide an immediate social context that adolescents select into, but also a social group that influences individual behaviors (Crosnoe and Johnson, 2011). Much research has been dedicated to the first problem - drinking behavior (e.g., Ennett et al., 2006; Gaughan, 2006; Christie-Mizell and Peralta, 2009), while less has been allocated to the social selection problem - though the attentional imbalance is slowly shifting.

The two decisions - choosing to drink and selecting into situations providing drinking opportunities - appear to work together (Kirke, 2004). Recent research using new methods tackles these issues by linking changes in alcohol use to friendship network changes to assess whether friend selection and influence compete or mutually reinforce each other (Snijders et al., 2007). Though recent findings about when influence and selection emerge during adolescence are contradictory (Mercken et al., 2012; Burk et al., 2012; Knecht et al., 2011; Osgood et al., forthcoming), findings are generally consistent with earlier research: friends influence decisions to drink, but teens also prefer friendships with others with similar drinking proclivities (e.g., Kirke, 2004; Cohen, 1977; Kandel, 1978). In other words, the choice to drink is partly a function of relationship decisions.

In fact, genes influence both the decision to drink and having friends who drink (Fowler et al., 2007; Cleveland et al., 2005), but genetic contributions are also moderated by friends' drinking behavior such that high friend drinking accentuates genetic influences (Guo et al., 2009). The contributions of gene-friend environmental interactions are likely underestimated because adolescents select into party environments and befriend others similar to them, however (Guo et al., 2009; Cleveland et al., 2005). There is thus widespread concern that failing to account for adolescents' choices to participate in social encounters where alcohol is used poses problems both for understanding teen alcohol use and tailoring effective interventions to mitigate teen drinking (Cohen, 1977; Kandel, 1978; Bauman and Ennett, 1996; Kirke, 2004; Ali and Dwyer, 2010).

We continue the trend in social selection research of emphasizing homophilous friendship selection, though we shift focus by dissociating creation (forming new friendships) and durability (maintenance or longevity of existing friendships) processes. Doing so allows us to consider the role of drinking in close friendships from different angles. Although scholars have considered differences in these friend processes for other outcomes (Van Zalk et al., 2010; Weerman, 2011; Billy and Udry, 1985), similar drinking studies have not yet been done. Doing so helps to clarify the nature of the interpersonal social opportunities that homophilous alcohol use selection creates and the extent to which it fosters social connections that integrate youth.

\subsection{Mechanisms of homophily: Assortativity and proximity}

Three general mechanisms explain social tie formation and longevity in social network research (Rivera et al., 2010). The first and most common, assortativity, posits that friendship creation and durability are based on similar-

2. We define "party" loosely as a social gathering of teens away from adult supervision, typically involving eating, drinking alcohol, and entertainment. Terms such as "drinking and partying" are intended to connote attending social gatherings unsupervised by adults where alcohol is being consumed. 


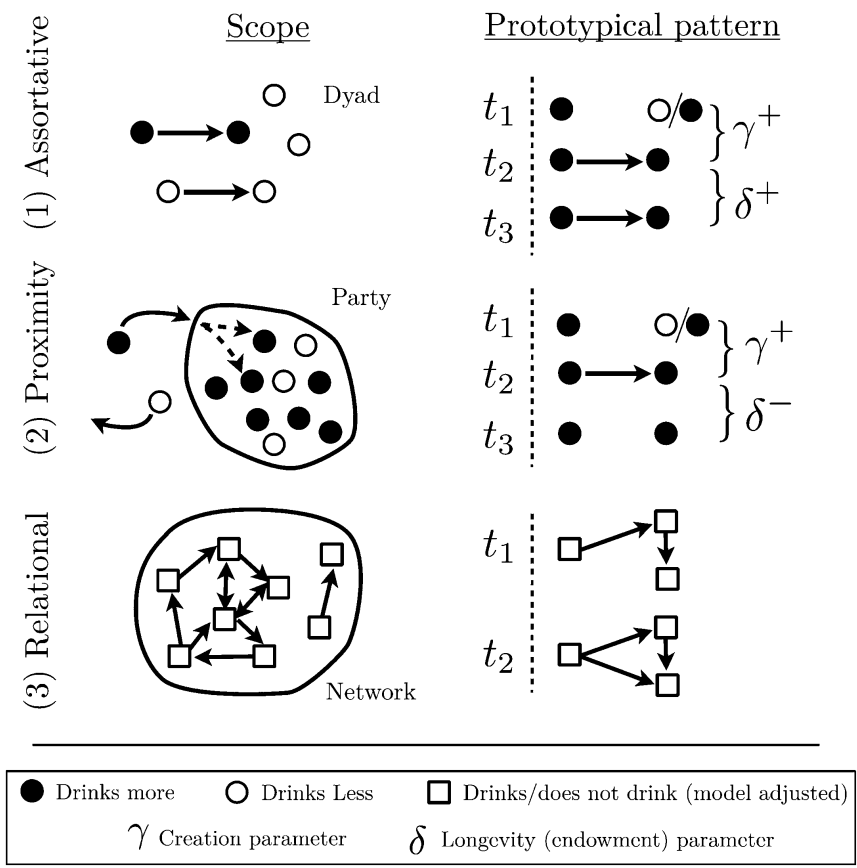

Figure 1. Scope and prototypical friendship change patterns for network mechanisms.

ities between individuals (Lazarsfeld and Merton, 1954; McPherson et al., 2001). Classical explanations of assortativity suggest that adolescents seek approval (Newcomb, 1956), balance (Heider, 1946), and/or social validation (Schachter, 1959) from their friends (see Hallinan and Tuma, 1978). As a result, similar individuals are more likely to form and maintain friendships with one another (Rivera et al., 2010).

This mechanism is depicted in two ways in Figure 1. First, the mechanism scope emphasizes its dyadic nature - adolescents prefer friendships with others who have similar drinking levels. Second, a prototypical change pattern shows a positive tendency towards homophilous friendship selection by depicting the creation of a tie linking drinker nodes between $t_{1}$ and $t_{2}$. Next, the expected durability pattern is indicated between $t_{2}$ and $t_{3}$ with tie persistence. In model-based terms, assortativity suggests positively signed parameters distinguishing between whether new friendships form or not $\left(\gamma^{+}\right)$, and whether existing ties persist or not $\left(\delta^{+}\right)$as functions of alcohol use similarity. The assortativity hypothesis is thus a two dimensional hypotheses proposing that adolescents prefer to form new close friendships with other teens who have similar alcohol use levels, and close friendships homophilous on alcohol use are more likely to be maintained over time. Prior studies assume that $\gamma^{+} \approx \delta^{+}$and so presume, rather than directly assess, that assortative friend selection is the basis for homophilous drinking selection.

A second mechanism, proximity, proposes that social foci structure social interactions in specific settings that adolescents select into (Feld, 1981, 1982). The basic idea is that when interactions oriented around social foci, such as drinking and partying, are successful, they produce positive sentiments (Doty and Wit, 1995), shared goals, and cultural norms of sociability that stimulate relationships and encourage people to return back to those and similar settings (Collins, 1981, 2004; Kahler et al., 2003). Viewed from the perspective of Turner's (1988) interaction theory, assortative and proximity selection mechanisms propose somewhat different dynamics. Turner (1988) emphasizes three mutually influential dimensions of social interaction: interaction, what happens when individuals come together, and how the interaction makes participants feel; structuring, how interactions are repeated and organized in time and space; and motivation, the desire to find new and renew prior interactions. While assortativity stresses the motivation for individuals to interact and the quality of those interactions, proximity mechanisms highlight motivations to participate in differentially structured social settings.

Figure 1 expresses the process scope with a non-drinker choosing not to party, and a drinker choosing to party; the environment is organized and structured around alcohol use. Because most teens at the party drink, drinkers have more interaction and friendship opportunities with other drinkers, increasing the probability that a homophilous friendship tie emerges (Feld, 1981). Notably, as a proximity mechanism, the role of drinking may be different than for other socially focused activities. For example, religious involvement is related to friendship selection in some schools (Cheadle and Schwadel, 2012), and many religious groups create systematic locational, temporal, and cultural supports for the socializing that happens in them - and so can strengthen durability. Drinking, in contrast, happens in transitory, unstructured environments, while capitalizing on neurobiological pathways to stimulate social ease, pleasure, and excitement, thereby heightening the intensity of socializing (Steinberg, 2008; Casey et al., 2011; Somerville and Casey, 2010). As a result, proximity-based alcohol selection may create social opportunities that are exciting and novel, and thus may encourage friendships at the expense of existing relationships (O'Malley et al., 1998). 
Teens drink to have fun (Leigh and Stacy, 1994; Lowe et al., 1997) and drinking intensifies emotions and psychological reactions to socializing (Smith et al., 1992; Doty and Wit, 1995; Pliner and Cappell, 1974). Moreover, the positive emotional influences of alcohol are contingent upon socializing (Doty and Wit, 1995) so that many youth select drinking environments not simply because friends attend them, but because they enjoy those settings and the social opportunities they afford (Kahler et al., 2003). To the extent that partying is the selection focus, rather than assortativity, proximity mechanisms create new friendship opportunities in a cycle promoting creation $\left(\gamma^{+}\right.$in Figure 1) but working against longevity $\left(\delta^{-}\right)$. In other words, drinking connects youth to social settings where alcohol is used, and while friendships emerge from those settings, so do new friendship opportunities. Thus, the proximity hypothesis is that adolescents prefer to form new close friendships with other teens who have similar alcohol use levels, but close friendships homophilous on alcohol use are less likely to be maintained over time.

For alcohol, assortativity and proximity mechanisms imply different patterns of social connection, and consequently different types of social integration. Assortativity suggests more durable friendships that can provide access to more consistent relationships with greater potential to provide access to support and resources. Proximity, in contrast, suggests less durable relationships so that while alcohol connects teens to one another, the relationships are more situational and superficial - and so may not create the same potential social benefits. In other words, alcohol would increase health risks (e.g., Bonomo et al., 2001) while generating less social capital (e.g., Crosnoe et al., 2003).

\subsection{Mechanisms of homophily: Relational}

The final mechanisms, which are relational mechanisms, propose that the shape and structure of networks influences friendships by conditioning trust, information, and interaction opportunities (Rivera et al., 2010). Reciprocity is one such fundamental network process. People tend to like others who like them and reciprocating relationships are less likely to be spurned (Newcomb, 1956; Montoya and Insko, 2008). As Simmel (1908 [1950]) noted, relational mechanisms also extend outward to higher-order friendship structures (i.e., triads), leading to network closure. Actors are inclined to create ties with the friends of their friends, for example, because people who interact with the same alters are more likely to socialize together (Granovetter, 1973; Feld, 1997). Figure 1 provides a prototypical transitive closure friendship creation pattern and a depiction of the mechanism scope (panel 3).

Because connections among similar drinkers could partly reflect reciprocation, triadic closure, and other mechanisms (Rivera et al., 2010) rather than assortative or proximity selection, relational mechanisms are important control parameters (see Steglich et al., 2010; Snijders et al., 2010). In addition, relational mechanisms such as degree processes (i.e., number of times viewed as a friend or number of friends reported) can interact with individual attributes to indirectly create homophily. For example, the social opportunities that alcohol is coupled with may increase friendship possibilities so that drinkers receive more friendship nominations (i.e., popularity; Dijkstra et al., 2009), or have more friends (sociability; Homish and Leonard, 2008). Importantly, Schaefer et al. (2011) show that these processes can lead indirectly to homophily. In their study, depressive symptoms lead to decreased sociability, marginalizing youth in the network, but also inducing homophily. Thus, controlling for links between alcohol-related popularity and sociability is important for understanding how drinking similarity leads to differential close friendship creation and maintenance patterns.

In addition, adolescent drinking may interact with network processes in other ways that have not been previously explored. Dyadic interactions are often transient and/or embedded in small groups with changing compositions, whether at parties or in other settings. Relational mechanisms structure these interaction opportunities through existing relationships. Successful interactions motivate returning to specific relationships (i.e., assortativity) and social activities (i.e., proximity) like drinking (Collins, 2004). Relational mechanisms suggest that friends' presence should structure-and, therefore, affect-interaction outcomes. Individuals come over time to more closely resemble friends' friends in terms of delinquency and other health behaviors (Payne and Cornwell, 2007; Christakis and Fowler, 2009), and alcohol use is related to structural cohesion and network transivity (Kreager et al., 2011). Although assortativity and relational mechanisms could create friendship clustering on drinking independently, friendship and alcohol use patterns may also capture preferences for friends whose friends drink similarly to them because consistency makes social interaction and environments more rewarding (e.g., Heider, 1946), thereby fostering and strengthening relationships at the dyad level.

Drinking similarity that adolescents have with their friends' friends may affect the creation and durability of existing dyad-level close friendships. That is, weaker social ties may condition stronger, close friendships. Teens may seek approval (Newcomb, 1956), balance (Heider, 1946), and/or social validation (Schachter, 1959) from friends' friends and not just the peers they are closest to. Thus, weak tie alcohol assortativity may more deeply embed adolescents into local social groups, fostering friendships and strengthening bonds that socially integrate them above and beyond closure relational mechanisms. At the same time, the positive emotional influences of alcohol are contingent upon socializing (Doty and Wit, 1995) so that many youth select drinking environments not simply because friends attend them, but because they enjoy drinking in those settings and doing so heightens excitement about the broad social opportunities they afford (Kahler et al., 2003). Friends' friends may thus contextualize dyadlevel associations around social foci like drinking and partying, fostering tie creation, but also undercutting friendship durability in a manner consistent with a proximity mechanism. 
Table 1. Descriptive statistics $(N=3561)$.

\begin{tabular}{|c|c|c|c|c|c|}
\hline Variable & Obs & Mean & Std. dev. & Min & $\operatorname{Max}$ \\
\hline Alcohol use, observation 1 & 2500 & 2.16 & (1.44) & 1 & 6 \\
\hline Alcohol use, observation 2 & 3556 & 2.15 & $(1.46)$ & 1 & 6 \\
\hline Female & 3561 & 0.49 & & 0 & 1 \\
\hline Grade & 3522 & 10.27 & (1.44) & 7 & 12 \\
\hline Non-white ${ }^{\underline{1}}$ & 1840 & 0.16 & & 0 & 1 \\
\hline White ${ }^{2}$ & 1717 & 0.06 & & 0 & 1 \\
\hline African American $\underline{2}$ & 1717 & 0.23 & & 0 & 1 \\
\hline Hispanic $^{2}$ & 1717 & 0.39 & & 0 & 1 \\
\hline Asian $\underline{2}$ & 1717 & 0.32 & & 0 & 1 \\
\hline Parent education & 2855 & 2.59 & (1.11) & 1 & 5 \\
\hline Parent drinks alcohol & 2849 & 1.80 & $(1.06)$ & 1 & 6 \\
\hline Alcohol is easy to get & 3539 & 0.28 & & 0 & 1 \\
\hline Regular smoker, observation 1 & 2505 & 0.11 & & 0 & 1 \\
\hline Regular smoker, observation 2 & 3558 & 0.22 & & 0 & 1 \\
\hline
\end{tabular}

\begin{tabular}{lllll} 
Network characteristics & $\begin{array}{l}\text { Middle } \\
(N=210)\end{array}$ & $\begin{array}{l}\text { Small } \\
(N=798)\end{array}$ & $\begin{array}{l}\text { Medium } \\
(N=832)\end{array}$ & $\begin{array}{l}\text { Large } \\
(N=1721)\end{array}$ \\
\hline Jaccard observation 1-2 (range: 0-1) & 0.42 & 0.47 & 0.33 & 0.30 \\
Jaccard observation 2-3 (range: 0-1) & 0.33 & 0.40 & 0.31 & 0.30 \\
Alcohol similarity (range: 0-1) & 0.83 & 0.74 & 0.67 & 0.70 \\
Alcohol similarity at distance = 2 (range: 0-1) & 0.87 & 0.79 & 0.81 & 0.82 \\
Average degree observation 1 & 3.95 & 3.79 & 5.13 & 2.91 \\
Average degree observation 2 & 3.25 & 3.31 & 4.31 & 2.29 \\
Average degree observation 3 & 2.31 & 2.75 & 3.58 & 1.96 \\
\hline
\end{tabular}

1. Includes the middle schools, small K-12th grade schools, and middle-sized high schools $(N=1840)$.

2. The large minority school.

\section{Data and methods}

The analysis employs the Add Health in-school assessment at wave 1 (observation point 1) along with the inhome waves 1 and 2 (observations 2 and 3) components. Add Health is a longitudinal stratified cluster sample of 7-12th grade youth begun in 1994 with in-school questionnaires administered to approximately 90,000 students in 140 schools. A nationally representative sample of over 20,000 students was then drawn from the in-school study, and data were subsequently collected in-home in 1995 and again approximately 1 year later at wave 2 . This longitudinal sample consisted of a special subsample of 16 "saturated" schools where friendship data were collected for all attending 7-12th grade students so that a network sample could be maintained over time. Of these 16 schools, two are mid-sized or large $(n>1000)$ and 14 are small $(n<300)$. The sample for this study utilizes 13 of these schools. Of the omitted schools, one was special education, and the other two middle schools had response rates inadequate $(<70 \%)$ for social network analysis (Huisman and Steglich, 2008; Kossinets, 2006).

The total sample size is 3561 adolescents, with 1721 coming from the large, racially heterogeneous high school, 832 from the middle sized predominantly white high school, and 798 and 210 coming from the seven small high schools and four middle schools, respectively. The middle sized and smaller schools were $16 \%$ minority, and the large minority school was $6 \%$ white, $23 \%$ black, 39\% Hispanic, and 32\% Asian. Network data were present for 69-92\% of students on school rosters. Missing data were handled within the estimation procedure with the composition change method (Huisman and Snijders, 2003), so that all youth were included in analysis and allowed to enter the study later or leave early (e.g., graduates, movers, dropouts). Missing alcohol and attribute data were treated as non-informative and imputed within the model following the method described by Huisman and Steglich (2008) (see also Huisman, 2009).

\subsection{Dependent variable and focal independent variable}

The dependent variable, the friendship network matrix, maps the interconnections between individuals and so captures the system and structure of relationships among adolescents in the 13 schools (see Wasserman and Faust, 1994). The adolescent friendship network is constructed from two sets of variables requesting nominations of up to five male and five female best friends from the school roster at each observation. ${ }^{3}$ The repeated, longitudinal as-

3. Due to a sampling error a subset of students was given only a single nomination opportunity at observation 2 . The result of this error is that the full friendship network was not captured for approximately $31 \%$ of the middle students, $40 \%$ of the small school youth, and $5 \%$ of those attending the medium white and large minority schools. We randomly carried either the observation 1 or 3 nominations forward or backwards in order to backfill the missing nominations. This approach allowed us to preserve the full network so that we could conduct the longitudinal social network analysis. A robustness analysis using the midsized school to randomly construct this issue in a "known" network showed that this method reproduced the proper estimates and performed better than ignoring the issue. 
sessments of the social network provides the analytic leverage for studying friend selection and thus social integration. The average adolescent had over 3.5 ties in the observed network.

Alcohol use frequency, the focal independent variable, is based on the question, "During the last 12 months, on how many days did you drink alcohol?" This item employs a standard alcohol use intensity assessment that was measured as a six-point scale with values for never drinks, once in the last year, once a month, 2-3 times last month, 1-2 times a week, and 3 or more times a week, respectively (Ali and Dwyer, 2010; Guo et al., 2009). Because alcohol use provides information on subsequent change in the network, only observation 1 and 2 are used. Descriptive statistics are provided in Table 1.

\subsection{Control variables}

Descriptive statistics for the control variables are presented in Table 1. An indicator for female is included to reflect the sex-stratified structure of adolescent social networks (Urberg et al., 1995). In addition, friend selection is related to both grade level and race/ethnic background clustering (Goodreau et al., 2009; Moody, 2001). Race/ethnic background is included in two ways to reflect compositional differences across schools. First, an indicator of nonwhite status for all schools except the large minority school is included, and, second, indicators of Hispanic, Asian, and white are included with African Americans serving as the omitted category in this school. In addition, the US is socioeconomically stratified, and adolescents self-stratify along these lines (Mouw and Entwisle, 2006). Parent education (observation 2) is included as a covariate with the following categories: did not graduate from high school, graduated from high school, some higher education, graduated from college, and obtained advanced schooling.

Three additional factors related to alcohol use are included. The first, drawn from observation 2, is how much the responding parent drinks alcohol $(1=$ never to $6=$ nearly every day). Not only do parents model alcohol use (Christie-Mizell and Peralta, 2009), higher than chance friend-parent similarity suggests that parent and friend proclivities intertwine in complicated ways (Rubin et al., 2006). Because access may support alcohol use selectivity, whether alcohol is easy to get (observation 2) is measured from the question "Is alcohol easily available to you in your home?" Finally, whether the youth is a regular smoker (ever smoked at least one cigarette a day for at least 30 days) is included as a time-varying covariate over the first two observation points because smoking, like alcohol, is a socially embedded activity that influences friend selectivity (Mercken et al., 2010) and is also correlated with alcohol use (Jackson et al., 2008).

\subsection{Analytic strategy}

The analysis employs the stochastic actor-based (SAB) model developed by Snijders $(1996,2001)$ and colleagues (e.g., Snijders et al., 2007) to models friendship network changes over time. Observation 1 is a starting point for estimation so that parameters capture changes in network statistics across observations. Coefficients are estimated using a method of moments routine capturing these changes in the network statistics between observations combined with an agent based simulation model that updates the parameters, estimates uncertainties, and provides an interpretational framework. The simulation model decomposes dyad-level changes in the network into a series of the smallest possible changes in one tie at a time for a randomly chosen focal adolescent. In this way, very complicated change patterns are modeled as the accumulation of many small changes in a way consistent with the aggregate observed change pattern. ${ }^{4}$

The selection model is thus concerned with tie changes in the friendship network, $x$ (omitting notation for time), where ties between ego ( $i$; rows) and alter $\left(j\right.$; columns) are denoted as $x_{i j}=1$, and the lack of a tie is $x_{i j}=0$. The linear predictor for adolescent friendship change, $f_{i}(x, v)$, for actor $i$ is defined in Equation (1) as

$$
f_{i}(x, v)=e_{i}(x, v)+c_{i}(x, v)+d_{i}(x, v)=\sum_{k} \beta_{k} s_{i k}(x, v)+\Delta^{+} \sum_{l} \gamma_{l} s^{+}{ }_{i l}(x, v)+\Delta^{-} \sum \delta_{l} s^{-}(x, v)
$$

$\beta, \gamma$, and $\delta$ are regression coefficients (in logits), and $s(x, v)$ are the effects defined in Table 2 (subscripts for $x$ and $v$ vary with the statistic considered). Vector variables, including alcohol use, are denoted $v$. In each micro-step where a tie change is considered, the configuration with the most positive $f_{i}(x, v)$ value with the inclusion of a random element relative to the current network configuration, $x^{0}$, determines how the network is modified (Snijders, 2001): (a) Either no change, (b) a new friendship is formed $\left(e_{i}(x, v)+c_{i}(x, v)\right)$, or (c) an existing friendship is terminated $\left(e_{i}(x, v)+d_{i}(x, v)\right)$. The model characterizes actor $i^{\prime}$ s modification of the network by choosing the maximal configuration across all other actors $(j)$. Adolescents make no change when $f_{i}\left(x^{0}, v\right)>f_{i}(x, v)$.

The three parts of the evaluation function $f_{i}(x, v)$ are: $(\mathrm{a}) e(x, v)$ assumes symmetry in both new friendship formation and keeping existing friendships so the $\beta_{k}$ capture the existence of a friendship (both creation and durability); (b) $c(x, v)$ models friendship creation only $\left(\Delta^{+}=1\right.$ for new friendships, 0 otherwise) with relationships expressed as $\gamma_{l}$ per Table 2/Figure 1; and (c) friendship durability (the 'endowment' function), $d(x, v)$, compares keeping versus dropping existing ties $\left(\Delta^{-}=1\right.$ for preexisting friendships, 0 otherwise) and is expressed by $\delta_{l}$. Thus,

4. The model is a continuous time Markov process in which each actor's decision on whether or not to change one tie or alcohol use is determined by the current state of his or her network configuration. Rate parameters govern how often actors have opportunities to make changes in either their network or alcohol use. Only one actor at a time can alter their network, actors cannot co-ordinate with each other, or plan beyond their current network state and the next state (Snijders, 2001). 
Table 2. Description of the model parameters.

\begin{tabular}{|c|c|c|}
\hline Parameter & $s_{i k}(x, v)$ & Description \\
\hline \multicolumn{3}{|l|}{ Effects associated with variables } \\
\hline Ego (focal adolescent) & $v_{i} \sum_{j} x_{i j}$ & Main effect of adolescent's own varname on the selection of friends (sociability) \\
\hline Alter (potential friend) & $\sum_{j} x_{i j} v_{j}$ & Main effect of potential friends' varname on the selection of friends (popularity) \\
\hline Ego $\times$ alter interaction & $v_{i} \sum_{j} x_{i j} v_{j}$ & $\begin{array}{l}\text { Expresses the tendency for adolescents with higher values on varname to prefer ties } \\
\text { to potential friends who likewise have higher values (this is a form of similarity that } \\
\text { increases with distance from the mean) }\end{array}$ \\
\hline \multirow[t]{2}{*}{$\begin{array}{l}\text { Ego } \times \text { alter interaction at } \\
\text { distance }=2\end{array}$} & $v_{i} \sum_{j} x_{i j} \hat{v}_{j}$ & $\begin{array}{l}\text { Expresses the tendency for adolescents with higher values on varname to prefer ties through } \\
\text { an intermediate friend to potential friends who likewise have higher values (this is a } \\
\text { form of similarity increasing with distance from the mean reflecting indirect connections) }\end{array}$ \\
\hline & \multicolumn{2}{|c|}{$\hat{v}_{j}=$ alters $^{\prime}$ alter $\bar{v}$} \\
\hline $\begin{array}{l}\text { Same varname (adolescent } \\
\text { and potential friend) })^{1}\end{array}$ & $\sum_{j} x_{i j} I\left(v_{i}=v_{j}\right)$ & Effect of the adolescent and the potential friend having an identical value on varname \\
\hline \multicolumn{3}{|l|}{ Effect paramaterizations } \\
\hline Evaluation effects & $e(x, v)$ & $\begin{array}{l}\text { The baseline effect paramaterization assuming symmetry between the creation and } \\
\text { dissolution of friendships }\end{array}$ \\
\hline Creation effects ${ }^{1}$ & $\Delta^{+} c(x, v)$ & Captures the creation of new ties \\
\hline $\begin{array}{l}\text { Endownment/durability } \\
\text { effects }^{1}\end{array}$ & $\Delta^{-} d(x, v)$ & Compares keeping existing ties to dropping them \\
\hline \multicolumn{3}{|l|}{ Structural parameters } \\
\hline Outdegree & $\sum_{j} x_{i j}$ & General tendency to choose a friend \\
\hline Reciprocity & $\sum_{j} x_{i j} x_{j i}$ & Tendency to have reciprocal friendships \\
\hline Transitive triplets & $\sum_{j, h} x_{i h} x_{i j} x_{j h}$ & Tendency to become a friend of a friends' friend (controls for transitive network closure) \\
\hline 3-Cycles ${ }^{2}$ & $\sum_{j, h} x_{i j} x_{j h} x_{h i}$ & Tendency for a friend's friend to chose the adolescent as a friend (generalized reciprocity) \\
\hline Number distance $=2^{3}$ & \multicolumn{2}{|c|}{$\#\left(j \mid x_{i j}=0, G=2\right)$ Tendency to be indirectly connected through one intermediary (controls for indirect connections) } \\
\hline
\end{tabular}

$k$ indicates statistics $s(x, v)$ that are held equal across creation-longevity processes, and $l$ statistics that differentially supply creation $c(x, v)$ and durability $d(x, v)$ contributions to actor $i$ 's decision $(k \neq l)$. This decomposition allows us to more directly address the role of drinking in social integration than other studies have been able to by formally operationalizing network mechanism/integration hypotheses.

The specific ways that covariates are operationalized to influence tie changes are presented in Table 2. Positive values on these effects contribute to the evaluation function and thus express preferences for ties, while negative values indicate the opposite. Alter (drinking and nomination receipt) and ego (drinking and nominating close friends) effects reflect the relationship between drinking and adolescent activity (i.e., popularity and sociability) and so are important relational mechanisms to control for. The ego-alter interaction effect is the assortative/proximity mechanism of homophily that we focus on for understanding how alcohol use is related to social integration. We have hypothesized that differences in creation-longevity suggest that alcohol use is related to alternative network mechanisms and thus different types of social integration. Notably, we also include the interaction between the ego's alcohol use and friends' friends average use (ego-alter at distance $=2$ ) in order to shed light on relational-assortativity and -proximity mechanisms. Additional statistics include structural parameters for reciprocity and transitive network closure are described in Table 2.

\subsection{Analysis}

The school-specific networks for the smaller k-12 schools were grouped into a single matrix and analyzed jointly as done elsewhere (Cheadle and Goosby, 2012; Cheadle and Schwadel, 2012). Rather than perform a metaanalysis across all schools together (Ripley et al., 2011), we chose to group the smaller networks by type to stabilize the estimation routine. Meta-analysis results across all schools for simpler selection-only models were virtually identical to results using the approach we have adopted here. ${ }^{5}$ The small schools, medium-sized mostly white, and the large urban minority school results were then combined using meta analysis. All results, from the model estimations on the three networks to the joint meta-analysis utilized the RSIENA software (Ripley et al., 2011).

5. The fact that the selection results are similar using this and meta-analysis methods gives us confidence that the results we present adequately capture the average effects across schools. Because the smaller schools are quite small, the estimation algorithm becomes unstable when models with creation and endowment functions were are estimated jointly so that we could not utilize these schools separately in our analysis. What we present here thus balances school heterogeneity with school inclusion. 
Table 3. Pooled log-odds coefficient estimates across schools from the combined meta-analysis for the focal model parameters $(N=3561)$.

\begin{tabular}{|c|c|c|c|c|c|c|c|c|c|c|}
\hline \multirow[t]{2}{*}{ Parameter } & \multicolumn{2}{|c|}{ Model 1} & \multicolumn{2}{|c|}{ Model 2} & \multicolumn{2}{|c|}{ Model 3} & \multicolumn{2}{|c|}{ Model 4} & \multicolumn{2}{|c|}{ Model $5^{b}$} \\
\hline & $\mathrm{b}$ & se & $\mathrm{b}$ & se & $\mathrm{b}$ & se & $\mathrm{b}$ & se & $\mathrm{b}$ & se \\
\hline Alter (nominated) & -0.01 & {$[0.02]$} & -0.01 & {$[0.02]$} & -0.02 & {$[0.02]$} & -0.01 & {$[0.02]$} & 0.00 & {$[0.02]$} \\
\hline Ego (nominate friends) & -0.08 & {$[0.03]^{*}$} & -0.08 & {$[0.03]^{*}$} & -0.08 & {$[0.03]^{*}$} & -0.08 & {$[0.01]^{*}$} & -0.06 & {$[0.02]^{*}$} \\
\hline Ego $\times$ alter interaction, creation & & & 0.04 & {$[0.01]^{*}$} & 0.15 & {$[0.01]^{*}$} & 0.07 & {$[0.02]^{*}$} & 0.06 & {$[0.02]^{*}$} \\
\hline Ego $\times$ alter interaction, durability & & & $\uparrow^{a}$ & -0.05 & {$[0.02]^{*}$} & -0.02 & {$[0.03]$} & -0.03 & {$[0.04]$} & \\
\hline Ego $\times$ alter at distance $=2$, creation & & & & & & & 0.45 & {$[0.06]^{*}$} & 0.50 & {$[0.08]^{*}$} \\
\hline Ego $\times$ alter at distance $=2$, durability & & & & & & & -0.49 & {$[0.04]^{*}$} & -0.64 & {$[0.07]^{*}$} \\
\hline
\end{tabular}

$* p<0.05$.

a. The upward arrow $(\uparrow)$ indicates that the parameter is held equal across the creation and durability functions.

b. The remaining parameters for the structural network and other control variables are shown in Table 4 .

Table 4. Remaining pooled log-odds coefficient estimates across schools for the full SIENA model from the combined meta-analysis $(N=3561)$.

\begin{tabular}{|c|c|c|c|c|c|c|c|c|}
\hline Parameter & $\mathrm{b}$ & se & & $\mathrm{b}$ & se & & $\mathrm{b}$ & se \\
\hline Structural parameters & & & Background variables & & & Race/ethnic variables & & \\
\hline Outdegree (density) & -3.10 & {$[0.43]^{*}$} & Female: alter & 0.00 & {$[0.03]$} & Non-white: alter & -0.02 & {$[0.05]$} \\
\hline Reciprocity & 1.98 & {$[0.24]^{*}$} & Female: ego & -0.07 & {$[0.03]^{*}$} & Non-white: ego & 0.12 & {$[0.06]^{*}$} \\
\hline Transitive Triplets & 0.53 & {$[0.12]^{*}$} & Female: same & 0.24 & {$[0.02]^{*}$} & Non-White: same & 0.16 & {$[0.10]+$} \\
\hline 3-Cycles & -0.48 & {$[0.12]^{*}$} & Grade: alter & -0.07 & {$[0.04]+$} & Hispanic: alter & 0.04 & {$[0.05]$} \\
\hline Number distance $=2$ & -0.18 & {$[0.02]^{*}$} & Grade: ego & -0.01 & {$[0.01]$} & Hispanic: ego & 0.00 & {$[0.05]$} \\
\hline Additional behaviors & & & Grade: ego $\times$ alter & 0.47 & {$[0.22]^{*}$} & Asian: alter & 0.29 & {$[0.05]^{*}$} \\
\hline Get alcohol: alter & 0.01 & {$[0.04]$} & Parent education: alter & 0.02 & {$[0.02]$} & Asian: ego & -0.13 & {$[0.06]^{*}$} \\
\hline Get alcohol: ego & 0.04 & {$[0.03]$} & Parent education: ego & 0.00 & {$[0.01]$} & White: alter & 0.25 & {$[0.08]^{*}$} \\
\hline Get alcohol: ego $\times$ alter & 0.05 & {$[0.05]$} & Parent education: ego $\times$ alter & 0.04 & {$[0.01]^{*}$} & White: ego & 0.46 & {$[0.08]^{*}$} \\
\hline Regular smoker: alter & -0.18 & {$[0.06]^{*}$} & Parent drinks: alter & 0.02 & {$[0.01]+$} & Race/ethnicity: same & 1.06 & {$[0.03]^{*}$} \\
\hline Regular smoker: ego & -0.01 & {$[0.03]$} & Parent drinks: ego & 0.01 & {$[0.01]$} & & & \\
\hline Regular smoker: ego $\times$ alter & 0.35 & {$[0.10]^{*}$} & Parent drinks: ego $\times$ alter & 0.01 & {$[0.01]$} & & & \\
\hline
\end{tabular}

$+p<0.10$

$* p<0.05$

\section{Results}

\subsection{Alcohol results}

Table 3 presents results for the focal alcohol use parameters across the 4-sets of 13 schools employed for the analysis. The model series begins with a simple model specification with parameters for reciprocity (not shown), alter (popularity $=$ received nominations), and ego (sociability $=$ nominations sent) effects to assess baseline social integration as a function of relational drinking mechanisms in Model 1. Model 2 adds their interaction to reflect baseline alcohol selection similarity in a way consistent with prior studies (i.e., assuming assortativity), Model 3 decomposes this effect into creation (new ties) and durability (maintain vs. drop an existing tie) effects. Model 4 adds to Model 3 by including both creation and durability effects for similarity at distance $=2$ measured by interacting ego alcohol use with the average alcohol use of friends' friends (i.e., alters' alters). Finally, Model 5 includes network structure and transitive closure processes plus all control variables and their ego, alter, and dyadic operationalizations. Model 5 thus controls for closure mechanisms, which comprise important relational selection mechanisms.

Results across the full model series indicates that alcohol use is unrelated to popularity as shown by the nonsignificant alter parameter $(b=-.01)$ capturing whether nomination receipt is related to alcohol use. In contrast, higher-using adolescents nominated fewer friends $(b=-.08)$, suggesting that drinkers' networks are more exclusive. ${ }^{6}$ Model 2 adds the ego-alter interaction, which has a small positive association with friend selection $(b=.04)$, indicating that drinking similarity between adolescents increases the likelihood of a friendship. This effect, however, assumes symmetry in tie creation and durability. Model 3 illustrates that this assumption is overly restrictive - peers who drink similarly are more likely to become friends (creation; $b=.15$ ), but homphilous dyads are less stable as indicated by the negative durability parameter $(b=-.05)$. These results - positive creation and negative durability - are consistent with the proximity hypothesis.

6. There does not appear to be a strong consensus about how alcohol use influences popularity and sociability. For example, Burk et al. (2012) report increased popularity in middle adolescence, decrease popularity in late adolescence, and increased sociability in early adolescence. Knecht et al. (2011) report no average effects, but substantial variation across networks, while Mercken et al. (2012) find only a small nonlinear decrease in popularity for the highest drinkers. There appears to be heterogeneity in the role that alcohol use plays in structuring adolescent friendship networks. 


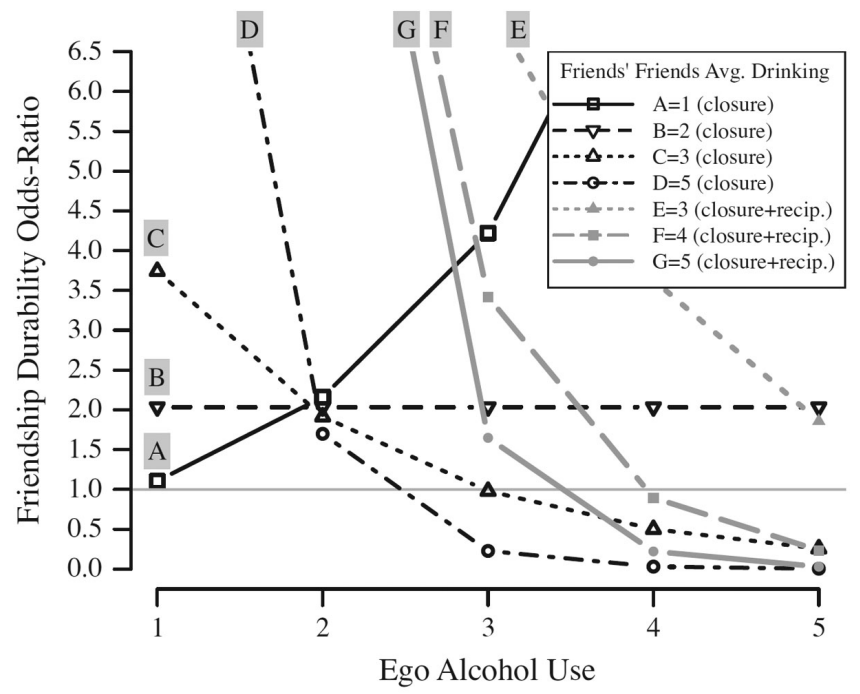

Figure 2. Line plots depicting the changing odds of friendship durability for different values of the focal adolescent's and existing friend's alcohol use, and friends' friends average alcohol use. Note: Alcohol use is held equal for friend and friends' friends average drinking. Curves A-D include ego, alter, ego * alter durability, ego * alter at distance $=2$ durability, transitive triplets, and number of friends at distance $=2$. Curves $E-G$ add the reciprocity term.

When similarity in drinking between egos and weak-tie (indirect) friendships (friends' friends) are considered in Models 4 and 5, the ego-alter creation effect is reduced by half, and the durability effect is reduced to nonsignificance. In comparison, the distance $=2$ ego times alters' alter drinking effects are large, and indicate that drinkers prefer that their close friends themselves have friends who drink $(b=.50)$. These dyad-level friendships are less stable $(b=-.64)$, however. The results thus suggest that dyad-level close friendships are influenced by the broader sets of other close friendships they are embedded within. To a focal adolescent, friends' friends likely constitute weak ties and these results may indicate that close friendships emerge out of a network of weaker relationships, strengthen, and then weaken again. In other words, there appears to be a link between strong ties measured as close dyadic adolescent friendships, and the weaker ties that connect adolescents into larger friendship groups in the case of alcohol use. The pattern, moreover, tends towards proximity selection, and thus favors a more superficial form of social integration.

In sum, alcohol use is a tool for social integration because adolescents with similar drinking profiles are more likely to connect to one another. These results are thus globally consistent with the idea that alcohol is a source of friendship homophily, but elaborate upon this hypothesis by showing that alcohol use works to connect drinkers both directly and indirectly, and not merely as a result of homophily at the dyadic level. Moreover, the effects of alcohol operate differently to promote the creation of new friendships and then subsequently influence their durability.

\subsection{Additional parameters}

Drinkers' direct connections to others who have friends with similar drinking levels are less durable. However, our models also adjusted for additional relational parameters that capture network closure processes. The findings presented are thus net of these effects. Next, we explore how these endogenous processes strengthen relationships by socially embedding adolescents into friendship groups. In essence, we ask how much drinking decreases close friendship durability when network closure and friendship reciprocity are considered. That is, when social embeddedness (i.e., other dimensions of integration) is jointly considered along with drinking. Table 4 shows the remaining results from Model 5, including the relevant structural parameters.

The combination of transitive triplets, 3-cycles, and the number of friends at distance $=2$ parameters indicate that some friendships reflect relational mechanisms. In this case, network closure. Indirect connections based upon alcohol use are more likely to become direct because these structural processes bring adolescents together socially, while the negative 3-cycles effect indicates tendencies towards local hierarchies. The intersection of these processes with friends of friends' alcohol use similarity is explored in Figure 2. We followed Ripley et al.'s (2011) recommendation to create ego-alter selection tables by calculating logit contributions to friendship durability (which we exponentiate). These two-way tables calculate predicted values for each level of mean-centered ego and alter alcohol use levels. Because of the high dimensionality of having a two-way table plus a third dimension capturing friends' friends average use, our calculations assume perfect homophily between the existing friend and their friends. Figure 2 is thus a graphical depiction of an ego-alter selection table that assumes both friend and friend's friends homophily, and that each friend's friends average is the same among all friends (because friends' friends is calculated across all friends in the estimation model). 
The first four curves depicted in Figure 2 show the odds of friendship durability when considering different friend and individual drinking levels, along with transitive network closure and friends at distance $=2$. Note that the durability curves are driven by the large ego-alter at distance $=2$ alcohol use interaction. Friendship durability is highest when friendships are heterophilous (when alter $\neq$ ego). Because average alcohol use is approximately 2-units, curve B shows that friendships are more durable among average drinkers and that relationship durability for them is driven by relational mechanisms $(\mathrm{OR}=2)$. For other groups, however, this is not the case. Odds are even for non-drinking homophily (A), for example, as they are for moderate drinkers (C), both of which are approximately 1-unit away from the mean. Durability is low even by ego use of 3-units when friends' friends' drinking is high (D). These results thus suggest that drinking, even accounting for relational mechanisms, is related to lower durability friendships.

Curves E-G add reciprocity to the equation. The idea being that reciprocity is a strongly stabilizing force that works with other network processes to embed adolescents into more durable dyadic relations. When included, the curves are shifted and favor friendship durability much more strongly. Heavier drinkers with friends who have friends who are also high drinkers, however, continue to have lower odds that friendships endure. These results show that relational processes have stabilizing influences on friendships, but also that homophily among high drinkers is related to turnover in friendships, and thus are consistent with the baseline interpretations of the model parameters in Table 3.

Returning to the other parameters in Table 4, being able to get alcohol easily is not related to friend selection. Although regular smokers are less popular, they are also more likely to become friends with one another. Friendships were also found to be homophilous on sex, grade, and parent education. Unexpectedly, girls nominate slightly fewer friends than do boys (Urberg et al., 1995). Notably, other SAB analyses using Add Health report no sex difference in friend nominations (Schaefer et al., 2011; Cheadle and Goosby, 2012; Cheadle and Schwadel, 2012), though these prior studies use different samples and only two waves of data. Because the first in-school network is included, our estimates may differ because of sex differences in friendship nomination patterns across adolescence, with younger girls nominating fewer friends than boys (Burk et al., 2012).

The race/ethnicity findings are complex and fleshing them out is beyond the scope of this paper. In general, adolescents prefer friends of the same race (non-white refers to the middle-schools, small k-12th grade schools, and medium sized schools; the other group-specific parameters refer to the large diverse high school). This is shown more strongly for the large minority school $(b=1.06)$, though the smaller effect $(b=.16, p<.1)$ in the homogenous white schools is nearly significant. Interestingly, minority youth in both the white schools and the minority school are more popular than youth in the majority (black and Hispanic youth in the large school), with Asian youth providing a notable exception. At the same time, in the large minority school Asian youth nominate fewer friends, which can produce homophily (Schaefer et al., 2011). These finding are interesting given recent findings that Asian youth in integrated schools have poorer outcomes (Goosby and Walsemann, 2012; Walsemann et al., 2011). The white youth in the large minority school, in contrast, are the most sociometrically active group.

\section{Discussion and conclusion}

Drinking can dangerously impair cognitive functioning, judgment, and behavior (Bonomo et al., 2001; Hingson et al., 2009), but its widespread incorporation into social settings also situates it as a mechanism for social integration (Rosenquist et al., 2010; Umberson et al., 2010; Crosnoe et al., 2004). We sought to explore this role by elaborating how teen-drinking similarity is related to close friendships. Our models distinguished between new and existing close friendships, and were motivated by the idea that similarities and differences in these processes provides a test of assortative and proximity selection mechanisms. We argued that network stability-change mechanisms emphasize different social interaction dimensions (i.e., Turner, 1988), and that clarifying the interactional foci suggests that drinking homophily is related to distinctive friendship change patterns for each mechanism. Moreover, friendship change-stability patterns have strong implications for whether drinking leads to deeper integration with a more consistent group of friends, or more superficial social integration characterized by less durable and more situational relationships.

Overall, the results conform most closely to proximity rather than assortative selection, and thus imply that friendships organized around drinking are more situational and superficial. When assortativity is assumed, the influence of homophilous alcohol selection on whether a close friendship is reported was small. The magnitude of this effect reflected differences in creation(+)-durability $(-)$ that counterbalance one another, decreasing the coefficient magnitude. A number of recent studies look at how alcohol and friendship are interlinked (Osgood et al., forthcoming; Burk et al., 2012; Knecht et al., 2011; Mercken et al., 2012), but may have misrepresented the selection process because assortativity was assumed by constraining the selection process to be equal for new and existing friendships. If alcohol use is generally related to proximity rather than assortativity, the basic (and most common) assumptions about how adolescent drinking selection works are wrong.

We further extended the selection process outward to model how similarity between individual and friends' friends drinking influences dyad-level associations. We suggested that this form of selection can be considered at the intersection of relational and proximity/assortativity mechanisms. Our view was that drinking and socializing do not happen strictly in dyads; rather, it happens in transitory social settings that condition dyad-level associations, helping to make them more or less successful, and thus positively or negatively influencing close friendship patterns (i.e., Collins, 2004). The results suggest that close friendships are in fact influenced by friends' friends in away that is also consistent with proximity selection. 
Thus, two separate views onto friendship selection suggest that homophilous drinking increases the likelihood that friendships form, but also that those relationships are less stable over time. These findings are important because assortativity is the general assumption while proximity mechanisms are less commonly studied. However, we distinguished assortativity from proximity indirectly. The argument is theoretical and we do not have information necessary to determine if friendships actually do or do not arise specifically in party environments, or turnover as functions of interactions in those settings. Moreover, the friendship change patterns used to make inferences about different network mechanism contributions may not work meaningfully for some outcomes like religion (Cheadle and Schwadel, 2012) or depression (Schaefer et al., 2011; Cheadle and Goosby, 2012), but may for other risk behaviors that are socially embedded in unstructured group settings away from adult supervision.

It is also important to remember that Add Health requested best friend nominations, and so our results are limited to only the closest friendships. We have attempted to be careful with our language because more distant adolescents are likely to be friends, just less close ones, and it is possible that measurement error lead to some mischaracterization of personal networks. The results should be viewed in light of these restrictions and possible biases. However, our interpretation is that our models illustrate a process by which closer friends emerge and fade back into loose friendship groups. Research utilizing more inclusive friendship networks with less restricted nomination rosters would help to illuminate these processes more clearly.

We have argued that these findings have implications for social integration. The shifting balance of friendship intensity and ways that drinking connects teens to social settings catalyzing new social opportunities can produce relationships where adolescents have less shared history together. Consequently, their "interaction ritual chain" histories are less intertwined (Collins, 2004), with the result that drinking homophilous close friendships may produce less social capital than is generally supposed (e.g., Hagan, 1991). For example, teens may be less motivated to support each other when stressed (e.g., romantic breakup, parent divorce), or capitalize on each other's social capital because understanding each other's needs is still developing. Viewing integration as a longitudinal process that interpersonal shared histories are embedded within suggests that the mechanisms of interpersonal connection can produce forms of integration that look equivalent cross-sectionally, but have different implications over time. Alcohol selection is selection on situations, so the social integration it produces may be more situational.

Understanding the distinctions and foundations underlying these mechanisms may hold the key for reconciling conflicting findings about when social influence and selection arise over adolescence, and what the balance is between these processes (Burk et al., 2012; Mercken et al., 2012). Neurodevelopmental models of adolescence, which we referenced in our theorizing about proximity mechanisms, propose that developmental asymmetries in control (i.e., prefrontal cortex) and socioemotional centers (e.g., striatum, domine system) of the brain lead to increased socializing and emotional responsiveness to social interactions (Steinberg, 2008; Casey et al., 2008). Moreover, alcohol use interacts with these systems (Hommer et al., 2011; Lovinger, 2008), further imbalancing them and predisposing adolescents to heightened emotionality, risk-taking, and sensation-seeking (Tapert et al., 2003). However, the balance between these systems changes over time (Steinberg, 2010; Gardner and Steinberg, 2005), which may alter the way that drinking alcohol is intertwined in developing adolescent friendships.

In other words, changing estimates of homophily found across adolescence in prior studies, and in creationdurability processes here, could reflect a complicated biosocial interaction capturing neurobiological changes that configure the relative importance of assortative and proximity mechanisms for facilitating social relationships. Specifically, one prediction of these neurobiological models is that assortativity is more salient among early adolescents and adults, but that proximity is elevated in middle adolescence in conjunction with risk-taking and sensation-seeking. The results presented here are thus consistent with neurobiological models positing that drinking homophily is tightly coupled to broad sets of social experiences in risky environments, and thus suggests a strong reciprocal link between individual agency and local social structure.

This work is limited in a number of ways. First, these results are based on selection-only models and do not control for friend influence. The model is thus exploratory in nature and there remains room to expand the parameterization, though doing so is computationally expensive for the larger schools. One outstanding question that elaborating the model in this way could address is whether the conditioning effects of friends' friends explain the influence effects of more distant associates on a broad set of behaviors (Kreager and Haynie, 2011; Payne and Cornwell, 2007; Christakis and Fowler, 2007, 2008, 2009). Second, the model itself makes assumptions about both the memories actors have of about their networks and the extent to which they coordinate their actions with each other (Snijders et al., 2010). Third, the longitudinal Add Health network sample is a convenience sample and there is more work to be done to determine how broadly representative the findings presented here are, in addition to how they vary across communities with different characteristics.

Despite these limitations, the analysis was theoretically motivated, novel, leveraged appropriate and innovative analysis techniques, and has implications for how we understand the role of alcohol use in connecting adolescents into close relationships with one another. Adolescents apparently form relationships homophilous on alcohol use because their preferences partially determine where and how they spend their time. Moreover, teen socializing is situated in broader, more diverse, and less cohesive friendship groups, and the wider pattern of drinking influences how close adolescents feel to their friends. The role of alcohol use in creating social integration is thus thornier than prior studies have indicated. Contrary to most discussions about adolescent friendship selection, the results show that social integration can be superficial and situational when considered from a dynamic framework, which would not have been apparent using cross-sectional data. 
Acknowledgments - This research was supported by a Grant from the National Institute on Alcohol Abuse and Alcoholism (R03AA019479, PI: Jacob E. Cheadle) and Grant K01 HD 065437 from the National Institute of Child Health and Human Development (principal investigator Bridget Goosby). This research uses data from Add Health, a program project directed by Kathleen Mullan Harris and designed by J. Richard Udry, Peter S. Bearman, and Kathleen Mullan Harris at the University of North Carolina at Chapel Hill, and funded by Grant P01-HD31921 from the Eunice Kennedy Shriver National Institute of Child Health and Human Development, with cooperative funding from 23 other federal agencies and foundations. Special acknowledgment is due Ronald R. Rindfuss and Barbara Entwisle for assistance in the original design. Information on how to obtain the Add Health data files is available on the Add Health website (http://www.cpc.unc.edu/addhealth). No direct support was received from Grant P01-HD31921 for this analysis. All opinions and errors are the sole responsibility of the authors and do not necessarily reflect those of either the helpful commentators or funding agencies sponsoring Add Health.

\section{References}

Albert, Dustin, Steinberg, Laurence, 2011. Judgment and decision making in adolescence. Journal of Research on Adolescence 21, 211-224.

Ali, Mir M., Dwyer, Debra S., 2010. Social networks effects in alcohol consumption among adolescents. Addictive Behaviors 35, $337-342$.

Bauman, Karl E., Ennett, Susan T., 1996. On the importance of peer influence for adolescent drug use: commonly neglected considerations. Addiction 91, 185-198.

Berkman, Lisa F., Glass, Thomas, Brissette, Ian, Seeman, Teresa E., 2000. From social integration to health: Durkheim in the new millennium. Social Science and Medicine 51, 843-857.

Billy, John O. G., Udry, J. Richard, 1985. Patterns of adolescent friendship and effects on sexual behavior. Social Psychology Quarterly 48, 27-41.

Bonomo, Yvonne, Coffey, Carolyn, Wolfe, Rory, Lynskey, Michael, Bowes, Glenn, Patton, George, 2001. Adverse outcomes of alcohol use in adolescents. Addiction 96, 1485-1496.

Burk, William J., Van Der Vorst, Haske, Kerr, Margaret, Stattin, Håkan, 2012. Alcohol use and friendship dynamics: selection and socialization in early-, middle-, and late-adolescent peer networks. Journal of Studies on Alcohol and Drugs 73, 89-98.

Casey, B. J., Jones, Rebecca M., Hare, Todd A., 2008. The adolescent brain. Annals of the New York Academy of Sciences 1124, 111-126.

Casey, B. J., Jones, Rebecca M., Somerville, Leah H., 2011. Braking and accelerating of the adolescent brain. Journal of Research on Adolescence 21, 21-33.

Cheadle, Jacob E., Goosby, Bridget J., 2012. The small-school friendship dynamics of adolescent depressive symptoms. Society and Mental Health 2, 99-119.

Cheadle, Jacob E., Schwadel, Philip, 2012. The 'Friendship Dynamics of Religion', or the 'Religious Dynamics of Friendship'? A social network analysis of adolescents who attend small schools. Social Science Research 41, 1198-1212.

Christakis, Nicholas A., Fowler, James H., 2007. The spread of obesity in a large social network over 32 years. The New England Journal of Medicine 357, 370- 379.

Christakis, Nicholas A., Fowler, James H., 2008. The collective dynamics of smoking in a large social network. The New England Journal of Medicine 358, 2249-2258.

Christakis, Nicholas A., Fowler, James H., 2009. Connected: The Surprising Power of Our Social Networks and How They Shape Our Lives. Little, Brown and Co., New York.

Christie-Mizell, C. André, Peralta, Robert L., 2009. The gender gap in alcohol consumption during late adolescence and young adulthood: gendered attitudes and adult roles. Journal of Health and Social Behavior 50, 410-426.

Cleveland, H. Harrington, Wiebe, Richard P., Rowe, David C., 2005. Sources of exposure to smoking and drinking friends among adolescents: a behavioral-genetic evaluation. Journal of Genetic Psychology 166, 153-169.

Cohen, Jere M., 1977. Sources of peer group homogeneity. Sociology of Education 50, 227-241.

Coleman, James S., 1961. The Adolescent Society: The Social Life of the Teenager and its Impact on Education. Free Press of Glencoe, New York.

Collins, Randall, 1981. On the microfoundations of macrosociology. The American Journal of Sociology 86, 984-1014.

Collins, Randall, 2004. Interaction Ritual Chains. Princeton University Press, Princeton, N. J. .

Crosnoe, Robert, 2011. Fitting In, Standing Out: Navigating the Social Challenges of High School to Get an Education. Cambridge University Press, New York, NY.

Crosnoe, Robert, Cavanagh, Shannon, Elder Jr., Glen H., 2003. Adolescent friendships as academic resources: the intersection of friendship, race, and school disadvantage. Sociological Perspectives 46, 331-352.

Crosnoe, Robert, Frank, Kenneth, Mueller, Anna Strassmann, 2008. Gender, body size and social relations in American high schools. Social Forces 86, 1189- 1216.

Crosnoe, Robert, Johnson, Monica Kirkpatrick, 2011. Research on adolescence in the twenty-first century. Annual Review of Sociology 37, 439-460.

Crosnoe, Robert, Muller, Chandra, Frank, Kenneth, 2004. Peer context and the consequences of adolescent drinking. Social Problems $51,288-304$.

Dijkstra, Jan Kornelis, Lindenberg, Siegwart, Verhulst, Frank C., Ormel, Johan, Veenstra, Rene., 2009. The relation between popularity and aggressive, destructive, and norm-breaking behaviors: moderating effects of athletic abilities, physical attractiveness, and prosociality. Journal of Research on Adolescence 19, 401-413.

Doty, P., Wit, H., 1995. Effect of setting on the reinforcing and subjective effects of ethanol in social drinkers. Psychopharmacology $118,19-27$ 
Ennett, Susan T., Bauman, Karl E., Hussong, Andrea, Faris, Robert, Foshee, Vangie A., Cai, Li, DuRant, Robert H., 2006. The peer context of adolescent substance use: findings from social network analysis. Journal of Research on Adolescence 16, 159-186.

Falci, Christina, McNeely, Clea, 2009. Too many friends: social integration, network cohesion and adolescent depressive symptoms. Social Forces 87, 2031- 2061.

Feld, Scott L., 1981. The focused organization of social ties. American Journal of Sociology 86, 1015-1035.

Feld, Scott L., 1982. Social structural determinants of similarity among associates. American Sociological Review 47, 797-801.

Feld, Scott L., 1997. Mathematics in thinking about sociology. Sociological Forum 12, 3-9.

Fowler, Tom, Shelton, Katherine, Lifford, Kate, Rice, Frances, McBride, Andrew, Nikolov, Ivan, Neale, Michael C., Harold, Gordon, Thapar, Anita, Van Den Bree, Marianne B. M., 2007. Genetic and environmental influences on the relationship between peer alcohol use and own alcohol use in adolescents. Addiction 102, 894-903.

Gardner, Margo, Steinberg, Laurence, 2005. Peer influence on risk taking, risk preference, and risky decision making in adolescence and adulthood: an experimental study. Developmental Psychology 41, 625-635.

Gaughan, Monica, 2006. The gender structure of adolescent peer influence on drinking. Journal of Health and Social Behavior 47, 47-61.

Goodreau, Steven M., Kitts, James A., Morris, Martina, 2009. Birds of a feather, or friend of a friend? Using exponential random graph models to investigate adolescent social networks. Demography 46, 103-112.

Goosby, Bridget J., Walsemann, Katrina M., 2012. School racial composition and race/ethnic differences in early adulthood health. Health and Place 18, 296- 304.

Granovetter, Mark S., 1973. The strength of weak ties. American Journal of Sociology 78, 1360-1380.

Guo, Guang, Elder, Glen H., Cai, Tianji, Hamilton, Nathan, 2009. Gene-environment interactions: peers' alcohol use moderates genetic contribution to adolescent drinking behavior. Social Science Research 38, 213-224.

Hagan, John, 1991. Destiny and drift: subcultural preferences, status attainments, and the risks and rewards of youth. American Sociological Review 56, 567-582.

Hallinan, Maureen T., Tuma, Nancy Brandon, 1978. Classroom effects on change in children's friendships. Sociology of Education $51,270-282$.

Heider, Fritz, 1946. Attitudes and cognitive organization. The Journal of Psychology 21, 107-112.

Hingson, Ralph W., Edwards, Erika M., Heeren, Timothy, Rosenbloom, David, 2009. Age of drinking onset and injuries, motor vehicle crashes, and physical fights after drinking and when not drinking. Alcoholism: Clinical and Experimental Research 33, 783-790.

Homish, Gregory G., Leonard, Kenneth E., 2008. The social network and alcohol use. Journal of Studies on Alcohol and Drugs 69, 906-914.

Hommer, Daniel W., Bjork, James M., Gilman, Jodi M., 2011. Imaging brain response to reward in addictive disorders. Annals of the New York Academy of Sciences 1216, 50-61.

House, J. S., Umberson, D., Landis, K. R., 1988. Structures and processes of social support. Annual Review of Sociology 14, $293-318$.

Huisman, Mark, 2009. Imputation of missing network data: some simple procedures. The Journal of Social Structure 10, 1-29.

Huisman, Mark, Snijders, Tom A. B., 2003. Statistical analysis of longitudinal network data with changing composition. Sociological Methods and Research 32, 253-287.

Huisman, Mark, Steglich, Christian, 2008. Treatment of non-response in longitudinal network studies. Social Networks 30, $297-308$.

Jackson, Kristina M., Sher, Kenneth J., Schulenberg, John E., 2008. Conjoint developmental trajectories of young adult substance use. Alcoholism: Clinical and Experimental Research 32, 723-737.

Johnston, Lloyd D., O'Malley, Patrick M., Bachman, Jerald G., Schulenberg, John, 2008. Monitoring the Future National Survey Results on Drug Use, 1975- 2007. National Institute on Drug Abuse, U. S. Department of Health and Human Services.

Johnston, Lloyd D., O'Malley, Patrick M., Bachman, Jerald G., Schulenberg, John, 2011. Monitoring the future national survey results on drug use, 1975-2010. vol. I: Secondary School Students. Institute for Social Research, Ann Arbor, The University of Michigan.

Kahler, Christopher W., Read, Jennifer P., Wood, Mark D., Palfai, Tibor P., 2003. Social environmental selection as a mediator of gender, ethnic, and personality effects on college student drinking. Psychology of Addictive Behaviors 17, 226-234.

Kandel, Denise B., 1978. Homophily, selection, and socialization in adolescent friendships. American Journal of Sociology 84, 427-436.

Kirke, Deirdre M., 2004. Chain reactions in adolescents' cigarette, alcohol and drug use: similarity through peer influence or the patterning of ties in peer networks? Social Networks 26, 3-28.

Knecht, Andrea B., Burk, William J., Weesie, Jeroen, Steglich, Christian, 2011. Friendship and alcohol use in early adolescence: a multilevel social network approach. Journal of Research on Adolescence 21, 475-487.

Kossinets, Gueorgi, 2006. Effects of missing data in social networks. Social Networks 28, 247-268.

Kreager, Derek A., Haynie, Dana L., 2011. Dangerous liaisons? dating and drinking diffusion in adolescent peer networks. American Sociological Review 76, 737-763.

Kreager, Derek A., Rulison, Kelly, Moody, James, 2011. Delinquency and the structure of adolescent peer groups. Criminology 49 , 95-127.

Lazarsfeld, Paul F., Merton, Robert K., 1954. Friendship as a social process: a substantive and methodological analysis. In: Berger, M., Abel, T., Page, C. (Eds.), Freedom and Control in Modern Society, Van Nostrand, pp. 18-66.

Leigh, Barbara C., Stacy, Alan W., 1994. Self-generated alcohol outcome expectancies in four samples of drinkers. Addiction Research and Theory 1, 335-348.

Lovinger, David M., 2008. Communication networks in the brain: neurons, receptors, neurotransmitters, and alcohol. Alcohol and Tobacco 31

Lowe, Geoff, Britton, R., Carpenter, E., Castle, H., Clayton, C., Hulme, C., Mara, D., Ormerod, J., 1997. Social drinking and laughter. Psychological Reports 81, 684.

McPherson, Miller, Smith-Lovin, Lynn, Cook, James M., 2001. Birds of a feather: homophily in social networks. Annual Review of Sociology 27, 415-444.

Mercken, Liesbeth, Christian, Tom A. B., Snijders, Steglich, Vertiainen, Erkki, de Vries, Hein, 2010. Dynamics of adolescent friendship networks and smoking behavior. Social Networks 32, 72-81. 
Mercken, Liesbeth, Steglich, Christian, Knibbe, Ronald, de Vries, Hein, 2012. Dynamics of friendship networks and alcohol use in early and mid-adolescence. Journal of Studies on Alcohol and Drugs 73, 99-110.

Montoya, R. Matthew, Insko, Chester A., 2008. Toward a more complete understanding of the reciprocity of liking effect. European Journal of Social Psychology 38, 477-498.

Moody, James, 2001. Race, school integration, and friendship segregation in America. American Journal of Sociology 107, 679-716.

Mouw, Ted, Entwisle, Barbara, 2006. Residential segregation and interracial friendship in schools. American Journal of Sociology $112,394-441$.

Newcomb, Theodore M., 1956. The prediction of interpersonal attraction. American Psychologist 11, 575-586.

O'Malley, Patrick M., Johnston, Lloyd D., Bachman, Jerald G., 1998. Alcohol use among adolescents. Alcohol Health and Research World 22, 85-93.

Osgood, D. Wayne, Ragan, Daniel T., Wallace, Lacey, Gest, Scott D., Feinberg, Mark E., Moody, James, forthcoming. Why do adolescents who drink have more friends? friendship dynamics and the emergence of alcohol use. Journal of Research on Adolescence.

Payne, Danielle, Cornwell, Benjamin, 2007. Reconsidering peer influences on delinquency: do less proximate contacts matter? Journal of Quantitative Criminology 23, 127-149.

Pliner, Patricia, Cappell, Howard, 1974. Modification of affective consequences of alcohol: a comparison of social and solitary drinking.

Ripley, Ruth M., Snijders, Tom A. B., Preciado Lopez, Paulina, 2011. Manual for RSIENA.

Rivera, Mark T., Soderstrom, Sara B., Uzzi, Brian., 2010. Dynamics of dyads in social networks: assortative, relational, and proximity mechanisms. Annual Review of Sociology 36, 91-115.

Rosenquist, Niels J., Joanne Murabito., James, Fowler H., Nicholas, Christakis A., 2010. The Spread of alcohol consumption behavior in a large social network. Annals of Internal Medicine 152, 426-433.

Rubin, Kenneth H., Bukowski, William, Parker, Jeffrey, 2006. Peer interactions, relationships, and groups. In: Eisenberg, N. (Ed.), Handbook of Child Psychology: Social, Emotional, and Personality Development, sixth ed. Wiley, New York.

Schachter, Stanley, 1959. The Psychology of affiliation: experimental studies of the sources of gregariousness. Stanford University Press, Stanford, CA.

Schaefer, David R., Kornienko, Olga, Fox, Andrew M., 2011. Misery does not love company: network selection mechanisms and depression homophily. American Sociological Review 76, 764-785.

Simmel, Georg, 1908. The Sociology of Georg Simmel. Free Press, New York.

Smith, Andrew, Kendrick, Anna, Maben, Andrea, 1992. Use and effects of food and drinks in relation to daily rhythms of mood and cognitive performance effects of caffeine, lunch and alcohol on human performance, mood and cardiovascular function. Proceedings of the Nutrition Society 51, 325-333.

Snijders, Tom A. B., 1996. Stochastic actor-oriented models for network change. Journal of Mathematical Sociology 21.

Snijders, Tom A. B., 2001. The statistical evaluation of social network dynamics. Sociological Methodology 31, 361-395.

Snijders, Tom A. B., Steglich, Christian, Schweinberger, Michael, 2007. Modeling the coevolution of networks and behavior. In: Montfort, K. V., Oud, J., Satorra, A. (Eds.), Longitudinal Models in the Behavioral and Related Sciences. Lawrence Erlbaum, London, pp. 41-71.

Snijders, Tom A. B., van de Bunt, Gerhard G., Steglich, Christian E. G., 2010. Introduction to stochastic actor-based models for network dynamics. Social Networks 32, 44-60.

Somerville, Leah H., Casey, B. J., 2010. Developmental neurobiology of cognitive control and motivational systems. Current Opinion in Neurobiology 20, 236- 241.

Steglich, Christian, Snijders, Tom A. B., Pearson, Michael, 2010. Dynamic networks and behavior: separating selection from influence. Sociological Methodology 40, 329-393.

Steinberg, Laurence, 2008. A social neuroscience perspective on adolescent risk-taking. Developmental Review 28, 78-106.

Steinberg, Laurence, 2010. A dual systems model of adolescent risk-taking. Developmental Psychobiology 52, 216-224.

Steinberg, Laurence, Morris, Amanda Sheffield, 2001. Adolescent development. Annual Review of Psychology 52, 83.

Tapert, Susan F., Cheung, Erick H., Brown, Gregory G., Frank, Lawrence R., Paulus, Martin P., Schweinsburg, Alecia D., Meloy, M. J., Brown, Sandra A., 2003. Neural response to alcohol stimuli in adolescents with alcohol use disorder. Archives of General Psychiatry $60,727-735$.

Turner, Jonathan H., 1988. A Theory of Social Interaction. Stanford University Press, Stanford, Calif. .

Umberson, Debra, Crosnoe, Robert, Reczek, Corinne, 2010. Social relationships and health behavior across the life course. Annual Review of Sociology 36, 139-157.

Urberg, Kathryn A., Degirmencioglu, Serdar M., Tolson, Jerry M., Halliday-Scher, Kathy, 1995. The structure of adolescent peer networks. Developmental Psychology 31, 540-547.

Van Zalk, Maarten Herman Walter, Kerr, Margaret, Branje, Susan J. T., Stattin, Håkan, Meeus, Wim H. J., 2010. It takes three: selection, influence, and deselection processes of depression in adolescent friendship networks. Developmental Psychology 46, 927-938.

Walsemann, Katrina, Bell, Bethany, Goosby, Bridget, 2011. Effect of school racial composition on trajectories of depressive symptoms from adolescence through early adulthood. Race and Social Problems 3, 131-145.

Wasserman, Stanley, 1980a. Analyzing social networks as stochastic processes. Journal of the American Statistical Association 75, 280-294.

Wasserman, Stanley, Faust, Katherine, 1994. Social Network Analysis: Methods and Applications. Cambridge University Press, Cambridge; New York.

Wasserman, Stanley S., 1980b. A stochastic model for directed graphs with transition rates determined by reciprocity. Sociological Methodology 11, 392- 412.

Weerman, Frank M., 2011. Delinquent peers in context: a longitudinal network analysis of selection and influence effects. Criminology $49,253-286$. 